\title{
A Phase II Study of Docetaxel and Oxaliplatin for Second-Line Treatment of Urothelial Carcinoma
}

\author{
Sandy Srinivas Lauren C. Harshman \\ Division of Oncology, Stanford University School of Medicine, Stanford, Calif., USA
}

\section{Key Words}

Metastatic urothelial cancer · Oxaliplatin - Docetaxel •

Second-line chemotherapy • Transitional cell carcinoma

\begin{abstract}
Background: Despite high response rates with front-line platinum-based therapies, $80 \%$ of patients with metastatic urothelial cancer progress. Multiple agents and couplets have been investigated, but no standard second-line regimen exists. We conducted a phase II study to evaluate the efficacy and safety of docetaxel and oxaliplatin in metastatic urothelial cancer patients who had received prior platinum therapy. Patients and Methods: Patients with metastatic urothelial cancer, who had disease progression after platinum therapy, were treated with docetaxel $75 \mathrm{mg} / \mathrm{m}^{2}$ and oxaliplatin $85 \mathrm{mg} / \mathrm{m}^{2}$ every 3 weeks until disease progression or intolerable toxicity. Results: Between November 2004 and September 2005, 11 patients were enrolled. All patients had low or intermediate Bajorin risk. The median number of cycles administered was 2 (range 2-8). One patient achieved near complete response. Three patients experienced disease stabilization, resulting in a disease-control rate of $36 \%$. Median overall survival was 7 months. The most common toxicities were fatigue and anemia (50\%). Conclusion: Second-line docetaxel and oxaliplatin in metastatic urothelial cancer is safe and tolerable but did not achieve an appreciable response rate.

Copyright $\odot 2009$ S. Karger AG, Basel
\end{abstract}

\section{Introduction}

Urothelial cancer is the fourth most common cancer in men in the United States [1]. Projections for 2008 include 125,490 new cases among both sexes and 27,810 deaths [1]. While early-stage urothelial cancer is curable, prognosis for patients with progressive or recurrent invasive urothelial cancer is generally poor.

Platinum-based therapies remain the most active regimens in advanced transitional cell carcinoma (TCC) of the urothelium and include MVAC (methotrexate, vinblastine, doxorubicin and cisplatin), cisplatin-gemcitabine and CMV (cisplatin, methotrexate, vinblastine) [2-4]. A randomized trial that compared MVAC with singleagent cisplatin in advanced bladder cancer demonstrated a significant response and survival advantage to the combination therapy, MVAC [2]. A prospective, randomized trial of MVAC compared with CISCA (cisplatin, cyclophosphamide and doxorubicin) again demonstrated the superiority of MVAC in terms of response and median survival [3]. Perhaps the most treatment-altering trial was a randomized trial comparing MVAC with combination cisplatin and gemcitabine, which demonstrated that the 2 regimens garnered similar response rates and median survival, but that cisplatin-gemcitabine was safer and elicited less intolerable toxicities [4].

While front-line regimens achieve impressive response rates of nearly $70 \%$ and improve median survival by 3

\section{KARGER}

๑ 2009 S. Karger AG, Basel

Fax +4161306 1234 E-Mail karger@karger.ch www.karger.com www.karger.com/che
Sandy Srinivas, MD

Department of Medical Oncology, Stanford Advanced Medicine Center 875 Blake Wilbur Drive

Stanford, CA 94305-1205 (USA)

Tel. +1 650725 2078, Fax +1 650736 1640,E-Mail sandysri@stanford.edu 
months, the majority of patients relapse following platinum-based chemotherapy. Investigation of second-line single agent and combination therapies has resulted in multiple treatment options including docetaxel, vinflunine, gemcitabine, paclitaxel, pemetrexate and ifosfamide [5-7], but despite copious investigation, no standard treatment has emerged due to modest response rates and no demonstrated survival benefit. In this setting, docetaxel has shown modest activity in patients pretreated with cisplatin, and oxaliplatin has shown tolerability $[8,9]$.

Investigating the combination of docetaxel and oxaliplatin in patients with relapsed or progressive urothelial cancer seemed a logical progression to improve upon the activity of docetaxel as a monotherapy in the second-line setting. Further rationale for the combination included the historically platinum-sensitive nature of TCC and the past success of oxaliplatin in combination with taxanes in other solid tumors. To evaluate the safety and preliminary efficacy of docetaxel and oxaliplatin in patients with advanced urothelial carcinoma who had progressed after prior platinum-based therapy, we conducted a phase II clinical trial on the hypothesis that the combination lacks pleiotropic resistance.

\section{Patients and Methods}

Eligibility required patients with metastatic urothelial carcinoma, who had had recurrence or progressive disease after one course of cisplatin- or carboplatin-based chemotherapy given perioperatively or for advanced disease. Inclusion required an Eastern Cooperative Oncology Group (ECOG) performance status of 0 or 1, measurable disease by Response Evaluation Criteria in Solid Tumors (RECIST, version 1.0), adequate hematologic (absolute neutrophil count 1.5 , platelets $>100,000$ ), renal (creatinine clearance $>50 \%$ or serum creatinine $<1.8 \mathrm{mg} / \mathrm{dl}$ ) and liver [bilirubin $\leq 2.0 \times$ upper limit of normal (ULN), serum glutamic pyruvic transaminase $($ ALT) $\leq 1.5 \times \mathrm{ULN} ;<4 \times \mathrm{ULN}$ if liver metastases present) function [10]. Patients were excluded at screening evaluation if they had brain metastases or $>$ grade 1 peripheral neuropathy. The protocol was approved by the Stanford University Institutional Review Board and Scientific Review Committee. All patients consented to participate and signed a written informed consent.

The treatment protocol consisted of docetaxel $75 \mathrm{mg} / \mathrm{m}^{2}$ intravenously over $1 \mathrm{~h}$ and oxaliplatin $80 \mathrm{mg} / \mathrm{m}^{2}$ intravenously over $2 \mathrm{~h}$ on day 1 . Cycles were 21 days in duration. Patients were premedicated with dexamethasone prior to docetaxel. Patients were continued on trial until disease progression or dose-limiting toxicities. Screening entailed a complete history and physical examination: documentation of weight, vital signs, performance status, a detailed history of prior urothelial carcinoma therapies, baseline laboratories including complete blood count with differential, comprehensive metabolic panel with liver function tests and serum creatinine, chest radiograph, as well as a computerized tomography (CT) scan of the chest, abdomen and pelvis.

At the beginning of each cycle, physical exam, laboratory monitoring of hematologic and end organ function and toxicity assessment were performed. Toxicity was graded using the $\mathrm{Na}-$ tional Cancer Institute Common Terminology Criteria for Adverse Events (version 3). CT scans were performed after every 2 cycles and evaluated using RECIST. Patients were discontinued from the trial for disease progression, grade 3 or 4 toxicity lasting more than 2 weeks, noncompliance, patient choice, or death. Patients were to be withdrawn from the study in the event that intercurrent or non-cancer-related illnesses prevented either continuation of therapy or regular follow-up. Patients could elect to withdraw from study treatment at any time for any reason.

A Simon 2-stage study design was used to assess the frequency and extent of antitumor activity of docetaxel in combination with oxaliplatin in metastatic urothelial cancer patients who had progressed after prior platinum therapy. A sample size of 33 was required to test the null hypothesis of a response rate of $20 \%$ or less by chance alone. The first stage was designed to accrue $11 \mathrm{pa}-$ tients. If 2 or fewer of those 11 patients responded by RECIST criteria, the trial would be halted and the regimen declared inactive in second-line urothelial cancer. Secondary objectives included assessments of toxicity and overall survival. Estimates of overall survival, which was defined as the time from initiation on the study treatment regimen to death from any cause, were determined using the product-limit method of Kaplan-Meier.

\section{Results}

Eleven patients were enrolled between November 2004 and September 2005. Eleven were evaluable for response and toxicity. Patient baseline characteristics are listed in table 1 . The majority of patients were male $(n=9)$. The median age was 65 years (range 57-81). All patients had a good performance status of ECOG 0 or 1 . Nine patients had primary bladder cancer, 1 patient had TCC of the renal pelvis, and 1 had primary urethral disease. The majority of patients had their primary site removed (radical cystectomy, nephroureterectomy). The reason for prior platinum treatment was for metastatic disease in $5(45 \%)$ and adjuvant treatment in 6 (55\%). Of the 5 who were treated for metastatic disease, 4 had a partial response and 1 had progressive disease on the platinum therapy. The majority of patients had nodal involvement $(n=7)$. Eight patients had visceral metastases, including bone $(\mathrm{n}=4)$, lung $(\mathrm{n}=$ 4 ) and liver $(n=3)$. The median time to relapse from prior chemotherapy was 11 months (range 2-22).

\section{Response and Survival}

The median number of cycles administered was 2 (range 2-8). The patient with primary urethral disease achieved a near complete response with only residual in- 


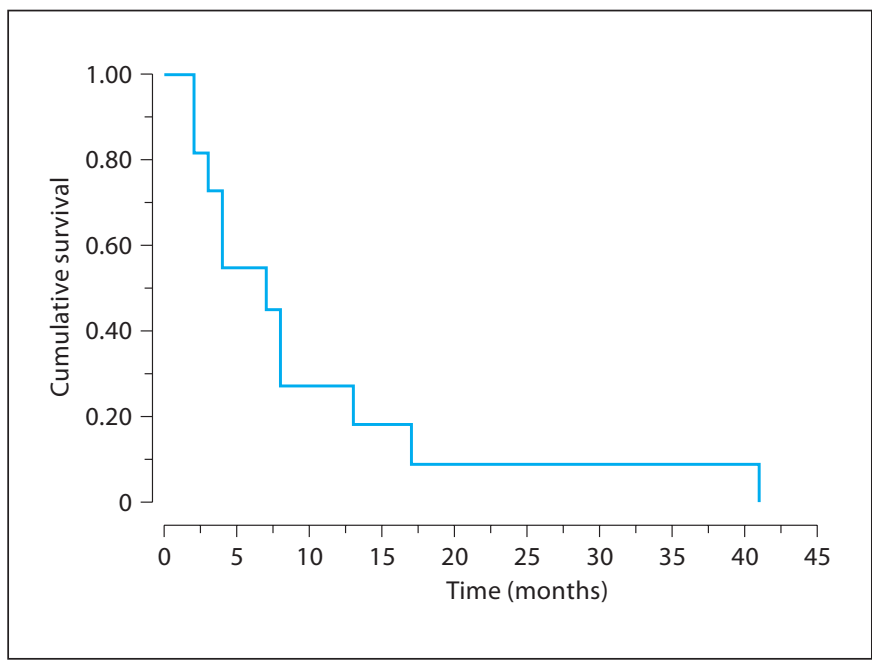

Fig. 1. Overall survival.

guinal nodal disease. She underwent nodal dissection with pathologic complete response. She remains disease free more than 3 years later. One patient had a $27 \%$ decrease in tumor burden in lung metastases and underwent surgical resection of a solitary residual metastasis. Unfortunately, he relapsed 3 months after his resection. Two other patients had stable disease. They both received 8 cycles prior to disease progression. The objective response rate was $9 \%$ and the disease-control rate was $36 \%$. Of the patients with complete response or disease stabilization, median time from platinum therapy was $>10$ months.

All patients except the one who experienced pathologic complete response have developed progressive disease and died. The Kaplan-Meier curve depicting overall survival is shown in figure 1 . The median survival for the entire cohort was 7 months (range 2-48).

\section{Toxicity}

All patients were evaluable for toxicity. There were no grade 4 toxicities or treatment-related deaths. Mild fatigue (grade 1) was the most common toxicity affecting $50 \%$ of the patients. Three patients $(18 \%)$ experienced grade 1, reversible neuropathy. Diarrhea was noted in 2 patients (11\%). One patient had grade 3 diarrhea that was proven to be secondary to Clostridium difficile colitis. Laboratory abnormalities included grade 1 anemia $(\mathrm{n}=$ 4), for which no transfusions were required, and a grade 1 increase in serum transaminases $(n=3)$. Other expected docetaxel toxicities observed included nail discoloration $(\mathrm{n}=1)$ and lower extremity edema $(\mathrm{n}=2)$.
Table 1. Pretreatment patient characteristics

\begin{tabular}{|c|c|c|}
\hline Characteristic & $\mathrm{n}(\%)$ & Range \\
\hline Male:female & $9(82)$ & \\
\hline Median age, years & 65 & $57-81$ \\
\hline \multicolumn{3}{|l|}{ ECOG performance status } \\
\hline 0 & 9 & \\
\hline 1 & 2 & \\
\hline \multicolumn{3}{|l|}{ Primary site } \\
\hline Bladder & $9(82)$ & \\
\hline Renal pelvis & $1(9)$ & \\
\hline Urethra & $1(9)$ & \\
\hline \multicolumn{3}{|l|}{ Prior surgery } \\
\hline Radical cystectomy & $8(72)$ & \\
\hline Nephrectomy & $1(9)$ & \\
\hline Partial cystectomy & $1(9)$ & \\
\hline Median number of platinum cycles & 4 & \\
\hline \multicolumn{3}{|l|}{ Reason for prior platinum } \\
\hline Adjuvant & 6 & \\
\hline First-line metastatic & 5 & \\
\hline \multicolumn{3}{|l|}{ Median interval between prior therapy } \\
\hline and study entry, months & 11 & $2-22$ \\
\hline \multicolumn{3}{|l|}{ Site of metastases } \\
\hline Lymph nodes & $7(64)$ & \\
\hline Bone & $4(36)$ & \\
\hline Lung & $4(36)$ & \\
\hline Liver & $3(27)$ & \\
\hline
\end{tabular}

\section{Discussion}

The majority of urothelial cancers are sensitive to chemotherapy. Cisplatin-based regimens such as cisplatingemcitabine or MVAC are clearly standard in the firstline setting given their ability to achieve remarkable responses and improve survival $[2-4,11,12]$. However, despite this exciting initial response rate, $80 \%$ of these patients relapse or progress and improvements in survival are modest at about 3 months [13].

Several poor prognostic factors have been identified for advanced urothelial cancer. Poor performance status, the presence of visceral metastases (e.g., bone, liver, lung), nontransitional cell histology, high lactate dehydrogenase, low hemoglobin, and high alkaline phosphatase (suggests liver or bone metastases) have all correlated with poorer survival in clinical trials [2, 13-16].

On review of our study patients who had achieved response or disease stabilization, it was not surprising that all had a good performance status and that the one patient who achieved pathologic complete response had only regional nodal disease (table 2). She had no Bajorin 
Table 2. Characteristics of patients who responded or had disease stabilization

\begin{tabular}{llllllllll}
\hline $\begin{array}{l}\text { Patient } \\
\text { No. }\end{array}$ & Response & $\begin{array}{l}\text { Age } \\
\text { years }\end{array}$ & Sex & ECOG & $\begin{array}{l}\text { Primary } \\
\text { site }\end{array}$ & $\begin{array}{l}\text { Site(s) of } \\
\text { disease }\end{array}$ & $\begin{array}{l}\text { Prior } \\
\text { treatment }\end{array}$ & $\begin{array}{l}\text { TTR after plati- } \\
\text { num, months }\end{array}$ \\
nisk group
\end{tabular}

TTR = Time to relapse; $\mathrm{OS}=$ overall survival; $\mathrm{pCR}=$ pathologic complete response; cis = cisplatin; gem = gemcitabine; $\mathrm{SD}=$ stable disease; carbo $=$ carboplatin. ${ }^{*}$ Months.

risk factors, and at the time of this analysis is alive and well at 48 months from the start of treatment, significantly surpassing the expected median survival of the Bajorin zero risk group of 33 months from the start of first-line therapy. But while the Bajorin model remains the only prognostic tool available, it is important to note that it has not been validated in the second-line setting. While the presence of visceral metastases and a low performance status likely still impart poor prognosis, other factors may impact response to second-line therapy such as response to first-line therapy, nature of response (complete or partial), duration of response to first-line therapy, and basis for administration of prior systemic therapy, i.e. adjuvant or metastatic setting [5].

Multiple agents have been studied as monotherapies in a second-line setting. Vinflunine, docetaxel, paclitaxel, gemcitabine, ifosfamide, topetecan and pemetrexed have been the most promising single agents given response rates of $10 \%$ or greater $[8,9,17-23]$. With the exception of vinflunine, no agent has moved beyond the phase II setting given the lack of demonstrated efficacy [24]. Clearly, there is a need for continued investigation based on rationally chosen combinations of agents.

In relapsed urothelial cancer, oxaliplatin has demonstrated tolerability but minimal activity as a monotherapy [9]. When combined with gemcitabine in treatmentnaive patients unfit for cisplatin-based therapy, the combination of gemcitabine and oxaliplatin proved active $[25$, 26]. It was this tolerability, demonstrated activity in frontline TCC, and success in combination in other solid tumors like gastric cancer and esophageal carcinoma that suggested that the utility of oxaliplatin in TCC might lie in combination with another active agent, such as docetaxel.

The taxanes have been evaluated in relapsed or platinum-refractory TCC due to their efficacy in the first-line setting. In one small series of 16 patients, methotrexate and paclitaxel in refractory TCC achieved a partial response of $37.5 \%$ with a 3 -month median duration of response and a median survival of 5 months [27]. Similarly, docetaxel monotherapy has demonstrated respectable response rates. In a phase II trial of 30 patients with treatment-naive metastatic TCC, docetaxel elicited a $31 \%$ response rate with 4 complete responders and a median duration of response of 6 months [28]. In patients who had received prior cisplatin-based therapy, docetaxel induced a $13.3 \%$ response rate in patients with nodal and soft tissue metastases [8]. Median overall survival was 9 months. Therapy was well tolerated with expected myelosuppression.

The demonstrated modest efficacy of docetaxel monotherapy in TCC, minimal overlapping toxicities, established responsiveness of urothelial TCC to platinums, and prior successful use of second-line oxaliplatin combinations in other solid tumors provided the rationale for the investigation of this combination. In general, the combination was quite tolerable with no grade 4 toxicities or deaths. Half of all the patients experienced mild fatigue. Neuropathy, a known complication of oxaliplatin and to a lesser degree of docetaxel, was observed in $27 \%$ of patients. The neuropathy was mild, grade 1 in nature, and reversible. Other expected oxaliplatin toxicities included diarrhea. Likewise, nail discoloration and lower extremity edema were observed consistent with expected docetaxel toxicity.

The regimen had a low efficacy. One exception was a patient with good risk features including an ECOG performance status of 0 , a primary urethral cancer, and no spread outside of local lymph nodes. This patient experienced a near complete response with the combination and was subsequently rendered a pathologic complete response by resection. The degree of disease stabilization 
was also notable (27\%), and the median survival was 7 months. Due to pretrial specifications of a minimum response rate, the trial was halted due to a lack of objective response by RECIST. However, the disease control seen in $36 \%$ of patients suggests that certain subsets of patients may benefit from this combination. Conclusions regarding median survival are limited by the small sample size and patient selection.

In summary, the combination of docetaxel and oxaliplatin was tolerable and resulted in 1 near complete response and 3 patients with disease stabilization. However, the majority of patients achieved no response, with
$64 \%$ of patients progressing on therapy within 2 months. A novel approach to the treatment of advanced treatment refractory urothelial cancer is greatly needed. Unconventional therapeutics targeting different etiological pathways or tailored treatment based on pretreatment expression of different genes such as ERCC1 may be key to future advances in the treatment of this disease [29].

\section{Acknowledgements}

This trial was supported by the Sanofi-Aventis Corporation. L.C.H. was supported by NCI/NIH T32 CA009287.

\section{References}

1 Jemal A, Siegel R, Ward E, Hao Y, Xu J, Murray T, Thun MJ: Cancer statistics, 2008. CA Cancer J Clin 2008;58:71-96.

-2 Loehrer PJ Sr, Einhorn LH, Elson PJ, Crawford ED, Kuebler P, Tannock I, Raghavan D, Stuart-Harris R, Sarosdy MF, Lowe BA, et al: A randomized comparison of cisplatin alone or in combination with methotrexate, vinblastine, and doxorubicin in patients with metastatic urothelial carcinoma: a cooperative group study. J Clin Oncol 1992;10:10661073.

$\checkmark 3$ Logothetis CJ, Dexeus FH, Finn L, Sella A, Amato RJ, Ayala AG, Kilbourn RG: A prospective randomized trial comparing MVAC and CISCA chemotherapy for patients with metastatic urothelial tumors. J Clin Oncol 1990;8:1050-1055.

4 von der Maase H, Hansen SW, Roberts JT, Dogliotti L, Oliver T, Moore MJ, Bodrogi I, Albers P, Knuth A, Lippert CM, Kerbrat P, Sanchez Rovira P, Wersall P, Cleall SP, Roychowdhury DF, Tomlin I, Visseren-Grul CM, Conte PF: Gemcitabine and cisplatin versus methotrexate, vinblastine, doxorubicin, and cisplatin in advanced or metastatic bladder cancer: results of a large, randomized, multinational, multicenter, phase III study. J Clin Oncol 2000;18:3068-3077.

5 Gallagher DJ, Milowsky MI, Bajorin DF: Advanced bladder cancer: status of first-line chemotherapy and the search for active agents in the second-line setting. Cancer 2008;113:1284-1293.

-6 Meriggi F, Di Biasi B, Caliolo C, Zaniboni A: The potential role of pemetrexed in gastrointestinal cancer. Chemotherapy 2008;54:1-8.

$\checkmark 7$ Read WL, Baggstrom MQ, Fracasso PM, Govindan R: A phase I study of bexarotene and rosiglitazone in patients with refractory cancers. Chemotherapy 2008;54:236-241.
McCaffrey JA, Hilton S, Mazumdar M, Sadan S, Kelly WK, Scher HI, Bajorin DF Phase II trial of docetaxel in patients with advanced or metastatic transitional-cell carcinoma. J Clin Oncol 1997; 15:1853-1857.

$\checkmark 9$ Winquist E, Vokes E, Moore MJ, Schumm LP, Hoving K, Stadler WM: A phase II study of oxaliplatin in urothelial cancer. Urol Oncol 2005;23:150-154.

10 Therasse P, Arbuck SG, Eisenhauer EA, Wanders J, Kaplan RS, Rubinstein L, Verwei J, Van Glabbeke M, van Oosterom AT, Christian MC, Gwyther SG: New guidelines to evaluate the response to treatment in solid tumors. European Organization for $\mathrm{Re}$ search and Treatment of Cancer, National Cancer Institute of the United States, National Cancer Institute of Canada. J Natl Cancer Inst 2000;92:205-216.

11 Harker WG, Meyers FJ, Freiha FS, Palmer JM, Shortliffe LD, Hannigan JF, McWhirter KM, Torti FM: Cisplatin, methotrexate, and vinblastine (CMV): an effective chemotherapy regimen for metastatic transitional cell carcinoma of the urinary tract. A Northern California Oncology Group study. J Clin Oncol 1985;3:1463-1470.

12 Sternberg CN, Yagoda A, Scher HI, Watson RC, Geller N, Herr HW, Morse MJ, Sogani PC, Vaughan ED, Bander N, et al: Methotrexate, vinblastine, doxorubicin, and cisplatin for advanced transitional cell carcinoma of the urothelium. Efficacy and patterns of response and relapse. Cancer 1989;64:24482458.

13 Saxman SB, Propert KJ, Einhorn LH, Crawford ED, Tannock I, Raghavan D, Loehrer PJ Sr, Trump D: Long-term follow-up of a phase III intergroup study of cisplatin alone or in combination with methotrexate, vinblastine, and doxorubicin in patients with metastatic urothelial carcinoma: a cooperative group study. J Clin Oncol 1997;15:25642569
14 Bajorin DF, Dodd PM, Mazumdar M, Fazzari M, McCaffrey JA, Scher HI, Herr H, Higgins G, Boyle MG: Long-term survival in metastatic transitional-cell carcinoma and prognostic factors predicting outcome of therapy. J Clin Oncol 1999;17:3173-3181.

15 Bellmunt J, Albanell J, Paz-Ares L, Climent MA, Gonzalez-Larriba JL, Carles J, de la Cruz JJ, Guillem V, Diaz-Rubio E, CortesFunes H, Baselga J: Pretreatment prognostic factors for survival in patients with advanced urothelial tumors treated in a phase I/II trial with paclitaxel, cisplatin, and gemcitabine. Cancer 2002;95:751-757.

16 Geller NL, Sternberg CN, Penenberg D, Scher H, Yagoda A: Prognostic factors for survival of patients with advanced urothelial tumors treated with methotrexate, vinblastine, doxorubicin, and cisplatin chemotherapy. Cancer 1991;67:1525-1531.

17 Albers P, Siener R, Hartlein M, Fallahi M, Haeutle D, Perabo FG, Steiner G, Blatter J, Muller SC: Gemcitabine monotherapy as second-line treatment in cisplatin-refractory transitional cell carcinoma - prognostic factors for response and improvement of quality of life. Onkologie 2002;25:47-52.

18 Culine S, Theodore C, De Santis M, Bui B, Demkow T, Lorenz J, Rolland F, Delgado FM, Longerey B, James N: A phase II study of vinflunine in bladder cancer patients progressing after first-line platinum-containing regimen. Br J Cancer 2006;94:1395-1401.

19 Dreicer R, Gustin DM, See WA, Williams RD: Paclitaxel in advanced urothelial carcinoma: its role in patients with renal insufficiency and as salvage therapy. J Urol 1996; 156:1606-1608 
-20 Lorusso V, Pollera CF, Antimi M, Luporini G, Gridelli C, Frassineti GL, Oliva C, Pacini M, De Lena M: A phase II study of gemcitabine in patients with transitional cell carcinoma of the urinary tract previously treated with platinum. Italian co-operative group on bladder cancer. Eur J Cancer 1998;34:12081212.

-21 Sweeney CJ, Roth BJ, Kabbinavar FF, Vaughn DJ, Arning M, Curiel RE, Obasaju CK, Wang Y, Nicol SJ, Kaufman DS: Phase II study of pemetrexed for second-line treatment of transitional cell cancer of the urothelium. J Clin Oncol 2006;24:3451-3457.

-22 Vaughn DJ, Broome CM, Hussain M, Gutheil JC, Markowitz AB: Phase II trial of weekly paclitaxel in patients with previously treated advanced urothelial cancer. J Clin Oncol 2002;20:937-940.

-23 Witte RS, Elson P, Bono B, Knop R, Richardson RR, Dreicer R, Loehrer PJ Sr: Eastern Cooperative Oncology Group phase II trial of ifosfamide in the treatment of previously treated advanced urothelial carcinoma. J Clin Oncol 1997;15:589-593.
24 Bellmunt Molins J, von der Maase H, Theodore C, Demkov T, Komyakow B, Sengelov L, Daugaard G, Caty A, Carles J, Morsli N, Dubois F: Randomised phase III trial of vinflunine (V) plus best supportive care (B) vs B alone as 2 nd line therapy after a platinum containing regimen in advanced transitional cell carcinoma of the urothelium (TCCU). (abstr 5028). J Clin Oncol 2008;26(suppl).

25 Carles J, Esteban E, Climent M, Font A, Gonzalez-Larriba JL, Berrocal A, GarciaRibas I, Marfa X, Fabregat X, Albanell J, Bellmunt J: Gemcitabine and oxaliplatin combination: a multicenter phase II trial in unfit patients with locally advanced or metastatic urothelial cancer. Ann Oncol 2007; 18:1359-1362.

26 Theodore C, Bidault F, Bouvet-Forteau N, Abdelatif M, Fizazi K, di Palma M, Wibault P, de Crevoisier R, Laplanche A: A phase II monocentric study of oxaliplatin in combination with gemcitabine (GEMOX) in patients with advanced/metastatic transitional cell carcinoma (TCC) of the urothelial tract. Ann Oncol 2006;17:990-994.
27 Bellmunt J, Cos J, Cleries R, Perez M, Ribas A, Eres N, Murio JE, Margarit C, Baselga J: Feasibility trial of methotrexate-paclitaxel as a second line therapy in advanced urothelial cancer. Cancer Invest 2002;20:673-685.

28 de Wit R, Kruit WH, Stoter G, de Boer M, Kerger J, Verweij J: Docetaxel (taxotere): an active agent in metastatic urothelial cancer; results of a phase II study in non-chemotherapy-pretreated patients. Br J Cancer 1998;78: 1342-1345.

29 Bellmunt J, Paz-Ares L, Cuello M, Cecere FL, Albiol S, Guillem V, Gallardo E, Carles J, Mendez P, de la Cruz JJ, Taron M, Rosell R, Baselga J: Gene expression of ERCC1 as a novel prognostic marker in advanced bladder cancer patients receiving cisplatin-based chemotherapy. Ann Oncol 2007;18:522528 . 